\title{
Acoustic Nerve Disorder NOS, CTCAE
}

National Cancer Institute

\section{Source}

National Cancer Institute. Acoustic Nerve Disorder NOS, CT CAE. NCI Thesaurus. Code C143260.

A disorder characterized by dysfunction of the acoustic nerve (eighth cranial nerve). 